\title{
Portfolio as a Stimulus for Improving the Work of Teacher Educators: An Experience at a College in the Arab Sector
}

\author{
Mahmood Khalil \\ The Academic College for Teacher Education, Sakhnin, Israel \\ Email: mahkh@macam.ac.il
}

Received 27 August 2014; revised 18 September 2014; accepted 23 September 2014

Copyright (C) 2014 by author and Scientific Research Publishing Inc.

This work is licensed under the Creative Commons Attribution International License (CC BY).

http://creativecommons.org/licenses/by/4.0/

(c) (i) Open Access

\section{Abstract}

The present article examines the contribution of building a portfolio to the professional development of teacher educators, and the effectiveness of their progress within the organized framework. The results of long-time research that was carried out in a college for teachers' education show the contribution of the derivative works that contain reflection and accompanies reflective thinking meetings for professional progress of teacher educators; for strengthening their motivation; for improving their level of education and ensuring its quality; to develop their involvement in the duty they are fulfilling and for a annual and future planning cultivation. Moral education, values and attitudes via acquiring knowledge in science content knowledge as Dreyfus (1995) emphasized that "biological knowledge is a prerequisite for the development of students' values and attitudes". Science knowledge role is not only for academic achievement and mastery of cognitive and metacognitive skills, but to educate students on the affective domain being active in the community life based on moral and ethical values, and positive attitudes toward societal issues, like social justice, preservation of the environment and peace, the last two being addressed due to the fact of having a mutual impact connection in one of the STS learning units presented.

\section{Keywords}

Curricula, Education, Inquiry, Content, Pedagogical Knowledge, Societal Issues, Ethics and Moral Values

\section{Literature Review}

Teaching portfolio is an academic document that contains the fields of responsibility for teachers, the philoso- 
phy of teaching, its goals and the teacher's accomplishments within their duty (Devanas, 2006). It is emerging as a significant tool for professional development and assessment of competence in teaching (Westhuizen \& Smith 2000). Teaching portfolio shows philosophy, which partially views an integral part of instruction-studying. This philosophy brings into account the procedure, the outcomes and the system of interaction between teacher educators and students in assessment, development and advancement (Katz, 1995).

Teaching portfolio begins mostly with background information upon which specific evidences appear through it. This background information ought to include a personal philosophy that describes the skills, values and goals of the portfolio owner (The University of Western Australia, 2005). Each portfolio is unique, yet they all include resources such as: professional articles and references with practical suggestions (Sullivan \& Glants, 2000), copies of the course material, syllabuses, reading material, study goals and instructions for studying, lab activities, modern projects and special activities within the framework of studying. Portfolios include also, examples of students' work with suggestions and corrections of drafts that shows the time and effort of teachers (Devanas, 2006), examples of finished or unfinished pieces of writing, pictures, video, researches and projects (Butler, 2006). The perception according to which the portfolio is built is flexible and could easily be matched according to the wishes of the person and the requirements that have to be fulfilled. This flexibility is what turns the portfolio into a highly powerful and useful tool (Meeus, Petgem, \& Looy, 2006).

Portfolios don't only serve as a documentation for the progression of new and effective activities, but also as a tool for teachers' development through reflection (Sullivan \& Glants, 2000). The reflection to a faculty upon their work enables them to forgo the daily details of teaching, and to analyze their effort in teaching (Devanas, 2006). The same critical thinking on achievement and understanding leads to, according to Shulman (Shulman, 2002), a higher thinking, which is expressed in the ability to employ judgment and planning in situations of blurring and uncertainty. In building a portfolio, which includes all those reflections, allows the teacher to be aware about their process of learning and to actually get to know that learning is a process that occurs all through their professional life, in parallel to their students' learning (Weinberger, 2006).

Sheloh, Sreft, \& Amousi (2002) view portfolio as a complicated and significant tool for professional evaluation of teachers, since it holds three types of information in teaching quality and professional activity for teachers: descriptive, evaluative and reflective. At Michigan State University (Michigan State University, 2008) teachers were asked to include the followings in their portfolio: 1) Evidence of course planning (syllabus, worksheets, assignments, tests and quizzes, group-project planning, lesson plans, list of teaching-aid tools); 2) Evaluation and feedback (evaluation of faculties/mentors and colleagues based upon their class visits, department's evaluation, students' feedback, personal evaluation); 3) Samples of students' work by their agreement (graded tests, journals, and graded assignments with comments); 4) Evidence of professional development (documents of attending seminars and workshops, documents for an article or a workshop in a professional conference, contribution to professional teaching periodicals, responses to pedagogical articles in periodicals, educational videos on request); 5) Evidence of excellence in teaching (scholarships, recognitions, and thank-you letters from students). Although the portfolio could be thick, it has to be concentrated, otherwise it will be hard to find cohesion and quality through it, especially when planning of goals and expectations is what turns collections to be one of a quality (Katz, 1995). Through teaching portfolio it is possible to view defined intentions in advance through evidences presented through it (Weinberger, 2006). That being the case, the question to be raised is: How many teacher educators are needed in order to create a beneficial portfolio? The University of Washington gave an answer to that question (Washington State University, 2007). It wrote tips to its faculty members for organizing and presenting portfolio: "Your teaching portfolio will not be effective if it is poorly organized, sloppy, or overly long. Here is a list of tools that can help you organize your portfolio in a way that will make it easy for the search committee to use your portfolio to evaluate your teaching effectiveness: Title page, table of contents, introduction or summary of portfolio contents, tab-separated sections, brief summaries of content for each section, a summary that reflects on evaluations and how you have used them to improve your teaching effectiveness. Present the portfolio in a neat and polished format. The point is not to dazzle the committee with an expensive and dramatic cover, but to be careful to present the material in a professional way”.

In addition to its contribution in improving teaching through designed evaluation, portfolio serves for summarizing evaluation as well. This evaluation is based on a wide variety of knowledge sources toward teachers' work, while having their permission to present their achievements. Using the portfolio along traditional evaluation tools (such as students' feedback), strikes the required balance for comprehensive evaluation. In fact, the portfolio's effectiveness as a tool of evaluating teachers, depends on the complete evaluation policy and in de- 
veloping the institutional model for evaluating the teaching personnel (Khalil \& Berger, 2005). Bird (1989) doubts that evaluating teachers is the primary purpose of the portfolio. According to him, portfolios have, first of all, to be significant for teachers, in a way that encourages high standards of specializing, personal development and learning that grows from within the field.

In the last few years the frequency of using portfolios in pedagogical frameworks has increased, and in training teachers in particular (Weinberger, 2006). It is considered a useful tool for professional learning and development; therefore teachers are requested to build portfolios more and more (Tillema \& Smith, 2007). Among others, portfolios are used as opinions for getting permanence in an educational institution or for teacher promotion (Bird, 1989). In other words, everything that represents the institution's purposes and could indicate the faculty's contribution to achieve them (instruction quality, professional activities, etc.) is suitable to be included in portfolios (Shiloh, Sreft, \& Amousi, 2002). There is no agreement between researchers about the basic standards and criterions needed to serve in evaluating teachers' portfolios. Approved and unique criterions may serve as guidelines for teacher educators, and for students who use portfolios. They may also create a common language between all of them in terms of evaluation. However, explicit criterions of evaluation may serve for building activities and professional development (Tillema \& Smith, 2007).

In fact, there are some difficulties in implementing the use of portfolio in general academic training and teacher training in particular. Education students (those who aim to be teachers) find it hard to understand what the significance of portfolio is, and they have a misunderstanding toward the role of portfolio in their training (Tarwijk et al., 2007). Those researchers show that the Dutch training systems have been trying for the past 10 years to implement an integral use of portfolio in training teachers following its success at medical schools in Holland. The experience they have gathered may serve as a source of inspiration and learning for teacher educators in other training systems around the world as well. The authors produced an analogy to include portfolios through the process they initiated. A simulated experiment was conducted to compare portfolios to other methods such as resumes and others to promote people in their work place. The experiment shows that using those analogies as part of education style deepens students' understandings and reveals to them the significance of portfolios.

Within the framework of activities to cultivate the quality of education at an Arab college for teacher education in the northern part of Israel, developing a tool for designing evaluation was planned-the personal portfolio. This process was first launched in 2002, when the college was established, and with the course of years this process was checked, tested and changes were conducted. Then it was realized in forms of applying the evaluation, its effectiveness and its influence upon the college's faculties. In this part, we shall shortly review the development of the process at the college through all its development steps during a period of five years.

At the beginning of the process, the portfolio formed the foundation stone to evaluate lecturers at the college and to improve their instruction quality. The process included a number of steps: co-learning for faculties in the field of designing evaluation in general and the features of portfolios as a tool of evaluation in particular; building the tool-discussions and cooperation in all steps of developing the tool; including the staff in the steps of building the tool; developing reflective writing; discussing and appointing a timetable for applying the process; regulations for introducing portfolios and their evaluations. The process of development included building the criterions' reserve, in which all faculty members took part. After discussions, the items that were deemed inappropriate for the college's teachers were shifted. Later, in the second year of implementing the process, the unit of research and evaluation that was established at the college was also included in the activities.

The process of preparing the portfolio was defined before the lecturers, based on designing evaluation policy at the college in terms of "experience that assists the teachers get knowing their job and enriches their learning, their professional and personal development" (The College of Sakhnin for Teacher Education, 2003). In addition to this, the goals of personal portfolios were defined through the surveys that were distributed to the lecturers. Those surveys serve as "an encouragement and certification for the personal and professional development of the members of faculty at the college". In order to increase the awareness regarding the significance of the portfolio academically and in terms of research, it was presented before the college's faculty members at several meetings during that academic year, while introducing the essence of its parts and its contribution to improve the education. In addition, the contents of portfolios were clarified and two portfolios built by faculties were presented as an example. Two essays were also sent to the faculty members touching on the same subject. In order to create a sense of cooperation and mutuality between the college and the lecturers, they were exposed to the significance of portfolios in order to create a sense of cooperation and mutuality toward the profit that will be 
gained by the college and the lecturers. Furthermore, the college's management indicated before the lecturers that determining clear and transparent regulations in evaluating lecturers pedagogically is highly significance. It also stressed on the issue of decision making, tenure and promotion of lecturers.

Following a survey for a number of methods for preparing portfolios in different academic colleges, the initial version of instructions to prepare portfolios was built, which included the following points: collegiate identification card (list of courses, duties, experience, etc.); resume; syllabus to every course; tracking-sheet after implementing the syllabus; sample course-planning; students' attendance; giving assignments and tracking them; evaluating lecturers by their students and getting reflective feedback of this evaluation; professional and personal development (continuing education programs, educational initiatives, conferences and research); participating in meetings; correspondences, planning new topics; implementing duties (yearly plans, five-year plan, activities on the internet website) and extending portfolios (The College of Sakhnin for Teacher Education, 2003). As for submitting the portfolio, it was agreed that the coordinator of the course, in cooperation with the lecturer, process the initial portfolio in accordance with the needs of the lecturer and the course. On the second stage, the coordinator of the course shall pass the portfolio together with his/her professional evaluation to the head of the college. After submitting the portfolios and having it evaluated by the management of the college, a personal meeting for every lecturer will be held with the head of the college.

In the 2003 academic year a number of changes were primarily made on the structure of the check list. The need for an evaluation sheet of the research unit was also changed to the requirement of combining the evaluation of people in charge from within the college (directors of courses, specialists and/or head of the college). That followed a discussion with the coordinators of courses, who noted the importance of the discussion and the shared reflection inside the course itself, on both a personal discussion between the teachers and the coordinator of the course and on a discussion between all the teachers of the course. The subject that received a significant attendance was reporting the intra-collegiate events that deal with organizing days of study, conferences, guest lectures and other events.

On the second year of applying designing evaluation using portfolios, the topic of the reflective survey that previously related to the "excellence in education" received special attention as a subject in its own. This subject contained two feedback questions: reflective feedback to evaluate lecturers by their students and portfolio's evaluation sheet. The first one is about reflective thinking toward the strength points and improving the lecturers according to what was expressed in the students' feedbacks. Based on this, lecturers were asked to infer what they had to design, develop and change following the feedback. The second one is about portfolio's evaluation sheet; it included considerations for selecting materials for portfolios, testing their contribution toward the personal development of lecturers and an explanation about its position toward the influence of portfolios on professional development. It is worth mentioning that all the lecturers were asked to focus on the same aspects relevant to their work and were also invited to relate to additional aspects that were not suggested on the check list. The two feedback questions served as a highly significant tool in putting the criterions of promoting lecturers' positions at the college. In addition, from the academic year 2003, reflective-thinking meetings with people in charge started to take place in front of the head of the college, while feedback meetings with the lecturers about portfolios were transferred to the responsibility of the courses' coordinators. People in charge were asked to fill a feedback sheet that included all their academic and administrative activities in and outside the college. During the meeting, reflection was provided over all the components, conclusions were developed over their activities and decisions were made over continuing a annual and future plan.

\section{The Research Question}

The primary question of this research is: what is the contribution of building a portfolio and reflective-thinking meetings to the advancement of teachers' professional development, and for its conduct's effectiveness in an organizational framework?

The characteristics of professional development and the conduct within the organizational framework for lecturers were grouped into five categories of content that constitute the basics of the research questions:

1) The professional conduct for some of the lecturers and people in charge and promoting it (employment in academic research, use of libraries and pedagogical centers, participating in study days in and outside the college, developing a teleprocessing environment).

2) Motivating people in charge for activities within the comprehensive organizational framework (Educational/pedagogical initiatives, communication with the management, annual and future plan). 
3) The level of education and insuring its quality (syllabus development, student's feedback, the teaching/ learning experience).

4) The extent of involvement in a duty (participating in meetings, functional orientation, communication with the lecturers on the course, marketing's advertisement).

5) Annual and future plan.

\section{Research Method}

Testing the effectiveness of portfolios and reflective-thinking meetings among lecturers and people in charge was carried out by collecting quality information of different types. First, all the documents related to the process of building portfolios, such as summarizing faculty meetings, informing letters to the lecturers, tests for building portfolios, etc. Then reflections of lecturers for building portfolios (30 reflections) were tested and in parallel there were the surveys that were given by the management about portfolios of lecturers between the years of 2003 and 2007 (35 surveys). In addition, reports of reflective thinking meetings that were filled by people in charge with the college president were surveyed and won joint reflection while having an intensive discussion that was documented on the same report (35 reports). The content categories for testing the results were based on a combination of categories introduced by the University of Michigan (Michigan University Press, 2008) and categories that emerged from the results and proved their presence.

It should be noted that despite the fact that the college declared that portfolios serve as a form of pedagogical opinion and decision making in terms of employment continuity, constancy and promotion, the college's management was forced to cope with many lecturers who didn't meet the requirements. Those lecturers received letters that expressed the significance of building portfolios and the consequence of their choice not to submit them. Based on that, a pedagogical opinion was written in their files that the lecturers did not work according to the requirements and the policy of the college. Furthermore, it was indicated that those who did not submit portfolios (as individuals or in an organized groups) shall bear the consequences regarding their position at the college.

\section{The Research Findings}

In order to test the effectiveness of portfolios and the reflective-thinking meetings as a tool for designing evaluation, we used the five content categories, described above. Now we will present the findings contributed to every category and support it with authentic examples.

\subsection{Testing and Improving the Professional Performance of Lecturers and People in Charge}

Surveys that were given to the lecturers by the college after testing their portfolios and summarizing the meetings of reflective thinking, show that the actual writing of portfolios, updates and discussions in reflective thinking meetings encouraged the members of faculty to launch a "self-examination" into their work and to expand their administrative and academic work. Testing feedback and a number of reports on reflective thinking meetings for the period of five years enabled testing the professional development of lecturers/people in charge in the following fields: work in research and academic publication, using libraries and pedagogical centers, participating in study days at the college and other colleges, and developing an electronic-learning environment.

First of all, it shall be noted that there is an increase in the attendance of lecturers in collegiate study days and in other organizations. There is also an increase of nearly a third in the number of initiatives for academic events. It is recognized that most lecturers (90\% in the fifth year of the process) participate in study days for the college, compared to $65 \%$ participation of lecturers and $78 \%$ in the third and the fourth year respectively. In fact, lecturers have even initiated study days in their field, such as organizing and launching a study day on learning disabilities and how to combine arts in teaching English. During the meetings of the surveys, more possibilities for launching study days with people in charge were checked, and it appeared that more than $87 \%$ of the initiatives were implemented. Participating in external study days was reported separately. It is noteworthy that participating in study days in various fields at universities, in conferences nationally and internationally and in different academic centers has also increased by about $10 \%$ from the third year of the process.

Secondly, it seems that there is an expansion in research and academic publication, which is the foundation of professional development. Most lecturers and people in charge (82\%) are working in research activities, either 
by participating in research committees within a discipline, writing academic articles or writing books. However, only half of the members of faculty were reported to have research activity or publication in the third year of the process. A few of them reported having some difficulty in combining teaching with research, yet they feel that research should be promoted among the members of faculty. The management familiarity with the direction of the research from the lecturers and people in charge enabled the management to mediate between them and appropriate bodies at the research unit. It also allowed them to contribute and encourage research activities at the college.

Thirdly, in testing the usage of the library and pedagogical centers by the lecturers and people in charge, it was found that there is a high regard for the library's activities and the pedagogical centre, as it appeared in letters from lecturers to the library's director and the pedagogical centre and to those were included in the portfolio. The lecturers' satisfaction increased from year to year on library's services, such as maintain the library's website, communicating with the faculty members, adding bibliographical information and subscribing to new periodicals. Moreover, many lecturers pointed out that they make an effort to visit the library and the pedagogical center on a constant basis, something that was not reported before. One of the lecturers stated: "I am updated with what goes in the library for English teaching and quite often, nearly once a week, visit the library. I also assist the students in selecting books for reading and assignments". The surveys' meetings stressed the significance of lecturers' and people in charge's attendance in such centers. As a matter of fact, there is a strong recommendation to expand their use and to serve as an example to students by simply being there. In addition, a responsibility was laid on the shoulders of some course coordinators to check the collection of books available in the library, to update it and to enrich it.

Fourthly, interdisciplinary integration was found as an issue that requires some investment and cultivation and it seems that its significance is known and understood by the lecturers, as one of the lecturers states: "I'm on a continuous and consistent contact with most lecturers in the same course and I attribute a high significance to this aspect. I act as the address for consultation, updates and doubts for many lecturers and I am happy regarding this". Furthermore, cooperation with other lecturers turns the material to be more relevant to students'. Out of those statements it appears that integration between disciplines, courses and practical work is taking place.

Fifthly, there seems to be a significant increase in the use of electronic-learning environment for lecturers' and students' needs. It turned out that developing an electronic-learning environment is a dominant component for most lecturers and serves all people in charge. Such component, which became available in the recent years, is expressed in the building of course-accompanying websites and the use of collegiate internet network. In the fifth year of the process, nearly $90 \%$ of the lecturers used a course-accompanying website. That was an increase of $15 \%$ and $20 \%$ compared to the fourth and third year, respectively. The lecturers indicate that students show a wise use of the course-accompanying websites. Efforts are being deployed to increase the students' awareness about the advantages of these websites, to encourage them to develop teaching material and to guide them in updating material to the website. It seems that the fact of obligatory reporting about this component produced the need "to fall in line" with the course of study to develop an electronic-learning environment, and to insert this component to the annual and future planning for courses and units in management.

\subsection{Increasing the Lecturers' and People in Charge's Motivation for Activities within the Comprehensive Organizational Framework}

This topic was first examined by lecturers and people in charge on different fields at the college. Studying the portfolios raised the issue that those initiatives grow basically among people in charge, and are mostly related to the cooperation with members of faculty. By analyzing the reflection, which the lecturers wrote throughout the process, it appeared that the reflection-thinking meetings encouraged cooperation of such a type and according to that they tested every initiative and project separately while evaluating and testing the continuity of activities in the future. So there was promotion and support to the activities in order to expand the limits of duty. Incentives were also received for participating in initiatives that include disciplines and strengthen the involvement of students in different projects' organizations.

The followings are a number of initiative examples that were introduced by people in charge and they were discussed during meetings of reflective-thinking:

"It is significant to be strict with a limited number of quality initiatives that integrate the goals and plans of the course. The most significant educational initiative for the course this year is the establishment of a 
pre-nursery”.

"I am a member in a committee that writes teaching plans to train people in charge in evaluating the report for the national education force. I have also initiated a continuing education program for the members of faculty”.

"In the framework of my duty as a coordinator of electronic-learning, I am busy most of the time in developing systems of electronic-learning and initiatives and implementing them among the members of faculty. I also organize meetings with the members of faculty outside office hours as well as arrange grants from the college and write books related to the field of education”.

Activities inside the college were tested in terms of communication with the management. It appears, based on the surveys, that this communication is open and effective-something that encourages a mutual and effective relationship. Recently, there seems to be a trend of desire and motivation among all the people in charge to improve their management and to make their work at the college more efficient. Although initially some reflections showed a highly formal relation, with launching the reflective-thinking meetings developments of open, mutual and supportive discussions were witnessed. The positive inspection is another thing worth pointing out. It is stemmed from the replies of people in charge and lecturers as they appeared in the report of reflectivethinking meetings in the last two years of the process, which were not actually reported in the first years of the process: "I, nearly every day, meet with the management and that is expressed in brief chats, which produces a relaxed, effective, open, and supportive environment; and there is a lot to learn". "Mutual, open, warm and effective contact. Excellent contact is a good example”. "An excellent contact with the management. The contact is developed throughout time in the most efficient way".

The managerial approach of "the opened doors" enables the lecturers and people in charge to be in unlimited contact with the management. Contact of such type enables mutual dialogue a continuous supervision and solves problems at the right time. Consequently, people in charge point out that they feel encouraged and supported by the management. One of the people in charge indicates: "I feel good in my work at the college. I feel that they recognize my work, which actually increases my desire and experience to perform my work in the best possible way, to be a 'wise head' and to think independently about possibilities and new directions that will contribute to the college instead of waiting for the head of the college to ask me to do that". It seems that such contact is a significant reason for the increase of new initiatives in the college and contribution for the lecturers' and peoplein-charge's desire to work, to advance professionally and academically.

\section{Inspection on the Education Level and Insuring Its Quality}

The lecturers and people-in-charge that serve as lecturers were required to point out their level of education, while considering their advancement on syllabus, students' feedbacks, teaching/learning experience, and for developing an electronic-learning environment. The lecturers were required to reflect on students' evaluations and to contend with expressing difficulties towards their teaching in their portfolios and during the reflective-thinking meetings with the head of the college. The meetings welcomed a joint inspectional-thinking, and in many occasions brought solutions to problems that were raised. It was an example of discussing solutions for classes struggling to ease the studying material, solutions to contend with teaching in a heterogeneous class and suggestions to improve plans and structures of courses. A follow-up to the process of implementing the solutions shows that nearly $78 \%$ of the solutions were implemented and the rest are being checked or changed.

The students' feedback presents a central point to the lecturers' supervision on the effectiveness of their teaching. It is important to point out that in the fifth year of the process most of the replies (nearly 93\%) that were written on the open part of the survey indicate that it was positive. On the other hand, in the first year only a small part (36\%) of the students wrote a positive survey in this part. The following is an example of a lecturers' summarizing evaluation in a reflective-thinking meeting: "Students are evaluated in class sociometrically and according to an indicator that elaborates the checked aspects. In this way, the students learn of others' mistakes and improve the aspects in which the tested people failed, so they would avoid losing points on their turn. The quality of the classes' outlines and the guidance material for the students are improving toward the end of the year”.

Sometimes difficulties are raised concerning passing the material, contending with the heterogeneity of a class or lowering the level of instruction. In the reflective-thinking meetings an effort is viewed in clarifying the dif- 
ficulties or finding ways to overcome them. That occurs by testing the solutions that were given in previous years and examining the situation again after following the recommendations. One of the lecturers in the meeting indicated: "I would teach the course in an entirely different way next year and as it was also planned for this year, twice a week, all throughout the year in order to accompany the students in implementing the guided experiment. The course is designed for an entire year and that helps to teach it in a more appropriate way next year".

The lecturers are ambivalent about the teaching/learning experience. The main reason for this dissatisfaction touches on students' difficulties in contending with the material. It appears that there is a variation in the students' basic level, which is the reason for the relatively slow pace in covering the courses' material. It appears that this delay in covering the material prevents the lecturers from expanding more into the course, which creates a feeling of frustration and boredom among the lecturers.

\section{The Extent of Involvement in Duty (for People-in-Charge)}

This topic was measured according to the participation of people-in-charge in meetings, functional orientation and contact with the lecturers, as well as testing the marketing publication of their unit.

The participation of people-in-charge in different meetings is a significant indicator for inspecting their involvement in their duty. The reflective-thinking meetings that were held together between the management and every person-in-charge separately and the thorough discussion on each of their to-do list, lead to examining the essence of the meetings, their structure, frequency and their effectiveness. The reports in portfolios about the extent of participating in the different meetings did not change fundamentally throughout the years. However, because of a survey that was received regarding its content, changes were considered and performed in accordance with the directors of courses and members of faculty.

It is worth mentioning first of all that most of them testified about the significance of consistent participation in most meetings. Meetings of people-in-charge and members of faculty meetings enjoyed the maximum attendance. The faculty members' meetings are viewed as a forum that contributes to the updating of every topic that deals with the collegiate activities on the macro level. On the other hand, disciplinary meetings that are based on the micro level of each and every course are being held. According to the replies it seems that those meetings create a productive discussion on different problems, suggesting ways to solve them and make them more efficient. The guidance meetings constitute a "fertile land" to nurse brains and consult with colleagues.

Furthermore, a positive survey for the people-in-charge was received regarding a full and active participation in meetings. Their importance was stressed in front of those who are less active. A discussion point that was raised was the make-up of participant in days of study. One of the female lecturers stated: "It is important that students should be able to take part in relevant days of study and to receive a clear explanation of what is being expected of them. Next year I will hold days of study for female teachers and female kindergarten teachers. I prefer days of study that serve the work of the course rather than open-for-public days of study". Another female lecturer wrote: "A day of study on including art in teaching English was held. It was very successful. The participation of schools and training teachers was a topic to be thought about".

The significance of functional orientation falls in the implications that a duty has, which a person-in-charge fills on his/her instruction. A discussion on such context contributed to strengthening the relation between filling the administrative duty and the academic instruction of courses to which this duty is related in one way or another. Out of the portfolios and feedbacks of reflective thinking it appears that the open mutual relations for the people-in-charge with the administration apparently serve as a model between the people-in-charge and lecturers. Most of them indicated a continuous, positive and consistent relationship with the lecturers. The significance they see in strengthening open mutual relationship is highly recognized, in order to advance knowledge exchange, respond to dilemmas and indecisions, being updated in occurrences and producing a positive environment.

The aim of inclusion for the marketed advertising of the portfolio for the people-in-charge was to show the activities and duties of so many in the college. It occurs by the assistance of the college's website and by the different means of communication for a wide audience in order to attract good students to the college. Simultaneously, and as a result of the reflective discussions, a marketing and advertising unit was established at the college, which helped the people-in-charge, especially in advertising the duties that they fulfill. One of the peoplein-charge stated: "the themes that arrive from communication forums indicate high standard views and organized vision to build the name of the college. Before inserting this function to the college, there was a spontaneous attendance of press, after inserting it, however, the college became an attraction spot to the press". 


\section{Annual and Future Planning}

One issue that received special attention was building an annual and future program. Inserting this component in the portfolio and to the meetings of reflective-thinking raised the awareness on the importance of thinking for an extended period. It also raised the awareness about testing the centre of activities for each course and the supervision on deciding on aims and goals and achieving them. The actual writing of the portfolio or holding meetings of reflective thinking forced the lecturers and people-in-charge to give statements about their work until then. Some of them reported on full implementation for the program and some reported on a partial one. One difficulty that was repeated again and again touched upon meeting the timetable in preparing the annual program until the preparation day. It seems that there is an understanding that meeting the timetable contributes largely to the ability of applying the aims and goals, but on the other hand organization for that is lacking. It appears that the actual interaction between the management and people-in-charge encourages to think about plans for next year and to advance thinking on initiatives and projects.

To sum up, we would bring together two opposite answers that relate to the efficiency of the portfolio as a tool for designing evaluations. The first reply, which was received from one of the female lecturers, shows the limitations of the tool. It considers its dependence on the written word and its systematic didactic structure:

"The significance of the process for me springs from the continuous desire and experience to learn, to be different and to be renewed. Such a process requires privacy and could not be summarized in writing. How could I describe all the complexities, disappointments, frustrations and hopes that accompany my job at the college in hard binders and chapters separated from each other by Bristol board? How could I describe the process slowly taking place and include learning, retreated growth, and regaining my composure among the staff, the students and myself? How could I describe the process taking place during classes, the abundance of understandings, insights and dilemmas at the end of each class, while preparing new lesson plans? How could I describe the long telephone conversations with my colleagues and the significant meetings with students? How could I describe the unique, strong relationships that get established between the members of faculty and the students despite the differences? I may distribute all of these things only by selecting the right person at the right time, and mostly in a direct way-face to face conversation”.

However, the second reply pointed toward the high contribution of the tool in evaluating the educational, academic work:

"Even though I initially refused to use a portfolio in my work as a lecture, I'm finding it now legitimate to thank you for this idea-though I have an experience of many years. The portfolio made me professionally improve in many aspects: More organization at work (building a yearly work-plan) supervision (syllabus, students, achievements, absence), work motivation (I always want to insert another idea and another project to the portfolio), participating in continuing education programs and days of study, reflection on students feedbacks and lectures. It was also a tool for self marketing (It helped me a lot in bids and job offers)”.

\section{Summary, Discussion and Recommendations}

The findings show that the process of preparing the portfolio, receiving feedbacks and the meetings of reflective-thinking contributed significantly to the professional conduct of lecturers and people-in-charge. The actual supervision, the shared reflection of their conduct and the opened features of the communication between them and the management are the main factors for this contribution. The four parameters of professional development are defined in both the portfolio and the meetings of reflective-thinking, while discussing the weaker elements for every answerer and finding ways to motivate them and widen their activities.

The portfolio and the meetings of reflective-thinking support new initiatives and tendencies, such as developing new computerized environments. It is done in a way that the obligation of reporting and preliminary inquiry in the same field motivates meeting expectations and regulations. The reporting of achievements has encouraged the members of faculty to launch a "self-examination" on their work while applying a reflection on their teaching's instruction and the components of their duty. This is defined in shared thinking on projects, days of study, changing the structure of instruction and encouraging research activities. In this way, the meetings of reflective thinking enabled the same "self-abnegation over the details of daily instruction and analyzing the success of lecturers” efforts in education’ as Devanas defined it (Devanas, 2006). It also appears that integration is being launched between the ranges of disciplines, between courses and the practical work. There is also an agreement that inter-disciplinary integration is an issue that needs to be cultivated and invested in. One of the significant 
contributions of the portfolio and the meetings of reflective thinking is that it encourages intra-collegiate and extra-collegiate educational initiatives. The head of the college was exposed to the hidden potential among lecturers and people-in-charge. Out of over-systematic viewing he had the power to assist different bodies, to create cooperation between them and expand their activities.

It seems that open and positive communication between management and members of faculty at the college influences the efficiency of their work. It also influences the ways problems are solved. Building the portfolio contributes to a personal awareness of each lecturer and person-in-charge, as the informal communication between them is reverberated on the meetings of reflective-thinking. It also increases their readiness to a real attention and actual contribution to the college. The significance of interaction between the teachers' educators and their students in integrating the process which they come across in building portfolios and the product itself, are significant components of their evaluation, development and academic progress (Katz, 1995).

The extent of inspection and supervision on the qualities of teaching increased following the portfolios and meetings of reflective-thinking. In addition, a platform was built for solving problems as well as overcoming difficulties while raising the awareness of their existence. The lecturers were requested to submit surveys' reports which they received from the different courses and that enabled them to realize the necessity of reflection on their work while examining different ways to improve the education in certain cases. The involvement of people-in-charge at their work is considered, according the findings, high in particular. It appears that the meetings constitute a "fertile land" for the discussions between colleagues together with the management in administrative and academic topics. (Shulman \& Shulman, 2004) stresses that strengthening the lectures' attitudes to learn from their experience and others' experience will motivate the process of metacognition reflection between the teachers themselves.

Discussion concerning functional orientation, which was raised in the meetings of reflective-thinking, strengthened the ties between fulfilling administrative duties and academic instruction in the relevant courses. During the first few years there were clear difficulties for the people-in-charge to see themselves as "sales persons" for the college through the duty they are fulfilling. The reflective discussions contributed to striking the balance between the three aspects of duty: academic, administrative and marketing.

Building portfolios and arranging meetings on reflective thinking were the most essential component in planning the annual activities and the future schedule for the lecturers and the people-in-charge. Given the fact that such component exists in portfolios, the opportunity was given to reflect initially on certain intentions through views that are presented on it (Wenberger, 2006). The personal and shared reflection with the head of the college raised the hidden potential in those meetings. A comprehensive recommendation that is raised from the findings touches on the difficulties of meeting annual and future planning until the day of preparing to open the new academic year. Following this difficulty, it is recommended that one launch to launch a guidance meeting for faculty members of faculty toward the end of the academic year. This should be devoted to annual and future planning and how it can be implemented to meet deadlines.

The difficulty in emphasizing the use of portfolios in academic training in general and teachers training in particular was revealed in this college too. In spite of the preliminary process that they have undertaken to train them to this mission, the management was forced to contend with a number of faculty members who did not meet the requirement. First, we have to raise the awareness of the members of faculty toward the importance of portfolios as a significant stimulus for professional development. An understanding should be emphasized that building a portfolio enables the teacher to be aware about his/her learning and to realize that learning occurs all through one's professional life-parallel to the learning of the student (Wenberger, 2006). One way of doing so is to encourage meetings of reflective-thinking to participate in faculty meetings and days of study, and to conduct research in and outside the college. Lecturers and people-in-charge are also encouraged to present their research work before the faculty members in order to stress the significance of this issue and to evaluate it. Similar to what Tartwijk and others (Tartwijk et al., 2007) did in their simulate experiment; they compared portfolios to a tool of advancing employees in their work. It might be initiated to launch an academic resource for the members of faculty, which would publicize the members of faculty on the internet, which one of its requests would be a summary of the same portfolio.

Secondly, following one of the lecturer's reply who saw some difficulty describing the complexity of education on the format of a portfolio, we should consider producing alternatives that will show the qualities of that portfolio. That's due to the disagreement between researchers toward the basic standards and criterions required to be used in evaluating portfolios for teachers, and due to the perception that the portfolio's intensity is depen- 
dent on its structure's flexibility, which can be adapted very easily to the wishes of the user and the requirements

of the context (Meeus, Petegem, \& Looy, 2006).

\section{References}

Bird, T. (1990). The Schoolteacher’s Portfolio: An Essay on Possibilities. In J. Millman, \& L. Darling-Hammond (Eds.), The New Handbook of Teacher Evaluation: Assessing Elementary and Secondary School Teachers (pp. 241-255). Newbury Park, CA: Sage.

Butler, P. (2006). eCDFePortfolio Project: A Review of the Literature on Portfolios and Electronic Portfolis. Massey University College of Education, Palmerston North, New Zealand. http://www.eportfoliopractice.qut.edu.au/docs/Butler\%20-\%20Review\%20of\%20lit\%20on\%20ePortfolio\%20research\%2 0-\%20NZOct\%202006.pdf

Devanas, M. (2006). A Summary of a 90-Minute Audio Conference. Teaching Portfolios: Improve Teaching and Personnel Decisions. The Teaching Professor and Magna Publications.

Katz, S. (1995). Alternative Evaluation in Education-Portfolio at the Nineties. Saanan Annual, 1, 105-116.

Khalil, M., \& Berger, E. (2005). Portfolio Assessment: The Impact on the Professional Development of College Teachers. 27th Annual EAIR Forum: Enduring Values and New Challenges in Higher Education. Riga: The European Higher Education Society.

Meeus, W., Van Petegem, P., \& Van Looy, L. (2006). Portfolio in Higher Education: Time for a Clarificatory Framework. International Journal of Education: Time for a Clarificatory Framework, 17, 135-127.

Michigan State University (2008). A Handbook for MSU Teaching Assistants 2008-2009 (TAP). 5th Edition, Michigan: Michigan State University.

Sheloh, Y., Sreft, R., \& Amousi, M. (2002). Developing a Portfolio for a New Teacher in Teachers’ Training College. In: B. Fresko, \& D. Kfir (Eds.), A Continuing Dialogue: Teacher Education and Educational Practice (pp. 290-314). Tel Aviv: MofetInstitut.

Shulman, L. S. (2002). Making Differences: A Table of Learning. Change, 34, 36-44. http://dx.doi.org/10.1080/00091380209605567

Shulman, L. S., \& Shulman, J. S. (2004). How and What Teachers Learn: A Shifting Perspective. Journal of Curriculum Studies, 36, 257-271. http://dx.doi.org/10.1080/0022027032000148298

Sullivan, S., \& Glants, J. (2000). Alternative Approaches to Supervision: Cases from the Field. Curriculum and Supervision, 15, 235-212.

Tartwijk, J. V., Rijswijk, M. V., Tuithof, H., \& Driessen, E. W. (2007). Using an Analogy in the Introduction of a Portfolio. Teaching and Teacher Education, 21, 15-31.

The College of Sakhnin for Teacher Education (2003). Formative Evaluation Policy in the College. Internal Document. Sakhnin: The College of Sakhnin for Teacher Education.

The College of Sakhnin for Teacher Education (2003). Personal Portfolio of College Teachers. Internal Document. Sakhnin: The College of Sakhnin for Teacher Education.

The University of Western Australia (2005). Evaluation of Teaching Unit, Centre for the Advancement of Teaching and Learning. Guidelines for Preparing a Teaching and Learning Folio. www.catl.uwa.edu.au

Tillema, H., \& Smith, K. (2007). Portfolio Appraisal: In Search of Criteria. Teaching and Teacher Education, 23, $442-456$. http://dx.doi.org/10.1016/j.tate.2006.12.005

Washington State University (2007). Creating a Teaching Portfolio. The Teaching Centre, Washington State University. http://teachingcenter.wustl.edu/About/ProgramsforGraduateStudentsandPostdocs/resources/Pages/Creating-a-Teaching-Po rtfolio.aspx

Weinberger, Y. (2006). Professional Development in Teacher Education: Use of Portfolio in the Pedagogic Instruction Setting. Dapim, Journal for Studies, Research and Teaching in Teaching Education, 41, 170-196.

Westhuizen, G., \& Smith, K. (2000). Teachers’ Potfolio Reflection: A Comparative Analysis. Teacher Development, 4, 352339. http://dx.doi.org/10.1080/13664530000200135 
Scientific Research Publishing (SCIRP) is one of the largest Open Access journal publishers. It is currently publishing more than 200 open access, online, peer-reviewed journals covering a wide range of academic disciplines. SCIRP serves the worldwide academic communities and contributes to the progress and application of science with its publication.

Other selected journals from SCIRP are listed as below. Submit your manuscript to us via either submit@scirp.org or Online Submission Portal.
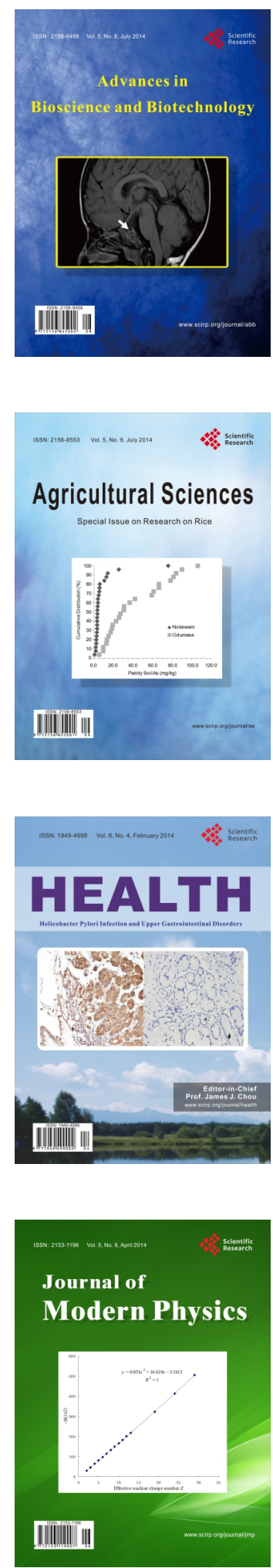
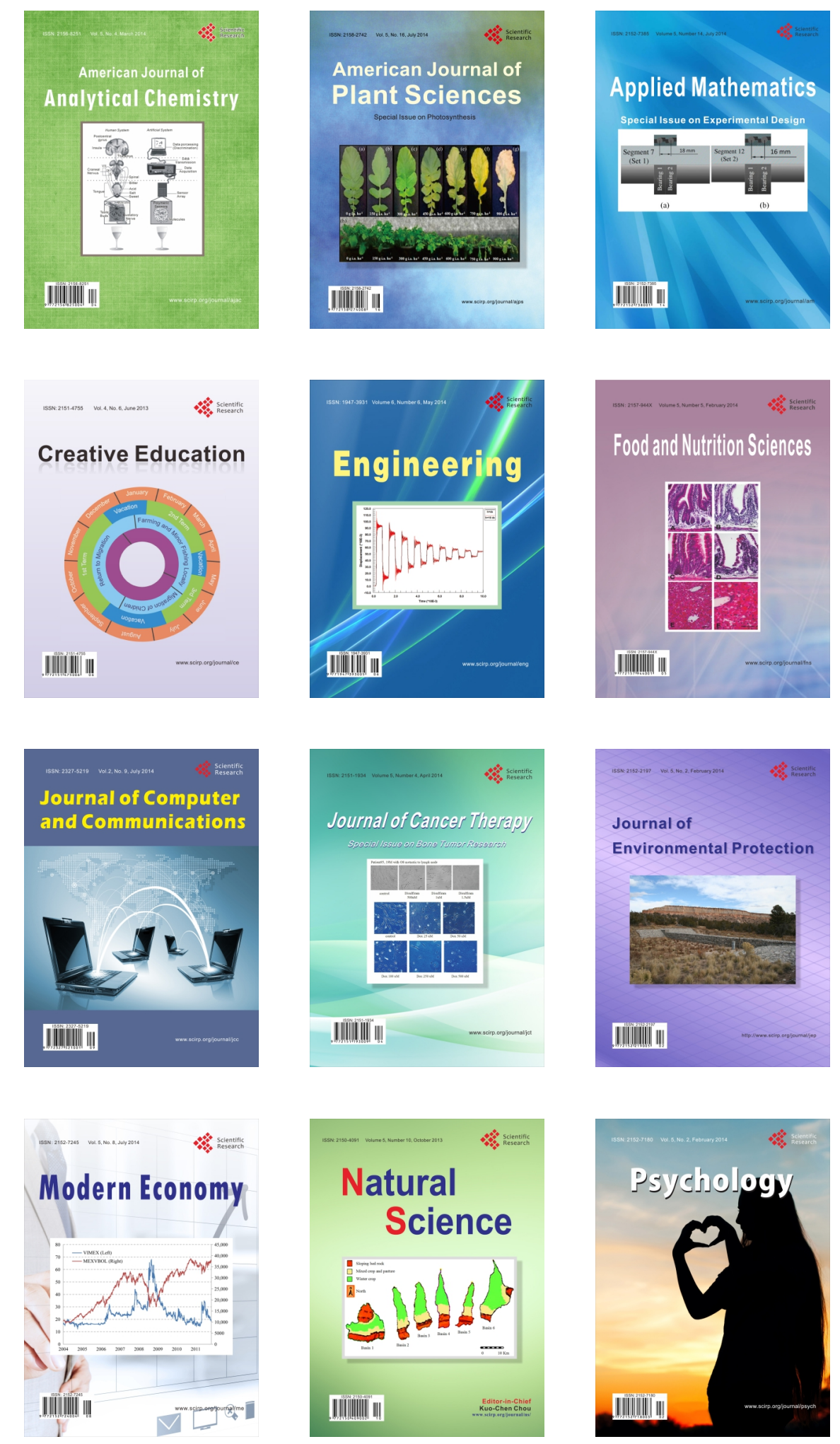